\title{
Preparation and application of a magnetic organic-inorganic hybrid nanocatalyst for the synthesis of $\alpha$-aminonitriles
}

\author{
ALI MALEKI*, RAZIEH FIROUZI HAJI, MINA GHASSEMI and HOSSEIN GHAFURI \\ Catalysts and Organic Synthesis Research Laboratory, Department of Chemistry, Iran University of Science \\ and Technology, Tehran 16846-13114, Iran \\ Email: maleki@iust.ac.ir
}

MS received 28 December 2016; revised 21 February 2017; accepted 22 February 2017

\begin{abstract}
This article is the first report of the catalytic application of copper ferrite-coated chitosan in organic reactions as a bio-nanocomposite. $\mathrm{CuFe}_{2} \mathrm{O}_{4}$ /chitosan was used as a hybrid nanocatalyst for the multicomponent Strecker synthesis of $\alpha$-aminonitriles by using aryl aldehydes, trimethylsilyl cyanide (TMSCN) and aromatic amines at room temperature in ethanol as a green solvent. The catalyst was characterized by Fourier transform infrared spectroscopy (FT-IR), thermogravimetric analysis (TGA), field-emission scanning electron microscopy (FE-SEM) and energy-dispersive X-ray spectroscopy (EDX) analyses. The nanocatalyst was recovered and reused several times without significant loss of catalytic activity. The organic products were obtained easily without need for column chromatography in good-to-excellent yields.
\end{abstract}

Keywords. Bionanocomposite; magnetic nanocatalyst; chitosan; $\alpha$-aminonitriles; green chemistry.

\section{Introduction}

Due to noteworthy role of catalysis in chemical processes, either in industry or science, nanocatalysts are highly important in this field. ${ }^{1}$ Multicomponent reactions (MCRs) are one of the most effective strategy in the field of green chemistry; which is the utilization of a set of principles that reduces or eliminates the use of or generation of hazardous substances in the design, manufacture and application of chemical products. ${ }^{2}$ Therefore, by application of the nanocatalysts in MCRs, chemical synthesis can approach aims of green and sustainable chemistry. Magnetic nanocatalysts as a subdivision of catalyst are an interesting category to design new strategy in green chemistry. On the other hand, chitosan as a natural polysaccharide-based biopolymer has attracted considerable recent attention in various chemical, medicinal and industrial applications because of diverse properties such as biodegradability, biocompatibility, non-toxicity and so on. ${ }^{3,4}$ It is used in many organic syntheses as a catalyst. ${ }^{5-8}$ Supporting chitosan with a magnetic nanocatalyst enhances its properties to yield green catalysts known as bionanostructures. ${ }^{9}$

$\alpha$-Amino nitriles are an interesting and useful class of intermediates for the synthesis of various nitrogencontaining heterocycles, $\alpha$-amino acids, amides and diamines. ${ }^{10,11}$ The Strecker reaction as the first MCR

*For correspondence between an aldehyde an amine and hydrogen cyanide is widely regarded in organic chemistry for the synthesis of $\alpha$-aminonitriles. ${ }^{12}$ They are very useful precursors for the synthesis of $\alpha$-amino acids, ${ }^{13,14}$ thiadiazoles and imidazoles ${ }^{15,16}$ and other biologically useful molecules. ${ }^{17}$ Recently, to improve the synthetic procedure, many catalysts have been introduced for the synthesis of $\alpha$-aminonitriles such as lanthanum(III)-binaphthyl disulfonate, ${ }^{18}$ nanocrystalline magnesium oxide, ${ }^{19}$ BINOL-phosphoric acid, ${ }^{20,21} \mathrm{~N}$-heterocyclic carbene (NHC)-amidate palladium(II) complex, ${ }^{22} \mathrm{Yb}(\mathrm{OTf})_{3}$ pybox, ${ }^{23} \mathrm{~K}_{2} \mathrm{PdCl}_{4},{ }^{24} \mathrm{~N}, \mathrm{~N}$-dimethylcyclohexylamine, ${ }^{25}$ superparamagnetic iron oxide ${ }^{26}$ and ionic liquid ${ }^{27}$ under various conditions. However, most of these methods require expensive reagents, long reaction times, harsh reaction conditions and tedious work-up procedures and give unsatisfactory yields. Considering these facts, there is still a need to introduce new, efficient, eco-friendly and inexpensive catalysts for this reaction.

In continuation of our interest in the application of new catalysts in organic synthesis via MCRs,${ }^{28}$ herein, an efficient and selective synthesis of $\alpha$-aminonitrile derivatives $\mathbf{4 a - 1}$ were carried out by using various aromatic aldehydes $\mathbf{1}$, amines $\mathbf{2}$ and trimethylsilyl cyanide $\mathbf{3}$ in the presence of a catalytic amount of magnetically recoverable chitosan-supported $\mathrm{CuFe}_{2} \mathrm{O}_{4}$ nanoparticles $\left(\mathrm{CuFe}_{2} \mathrm{O}_{4} /\right.$ chitosan $)$ in ethanol at ambient temperature in high yields (Scheme 1). The nanocatalyst can be recovered easily and reused without any significant loss of the catalytic activity. To the best of our 
$\mathrm{R}_{\mathbf{1}}^{\mathrm{O}}+\underset{\mathbf{P h}}{\mathrm{P}-\mathrm{NH}_{2}}+\underset{\mathbf{3}}{\mathrm{TMSCN}} \frac{\mathrm{CuFe}_{2} \mathrm{O}_{4} / \text { chitosan }}{\mathrm{EtOH}, \text { r.t. }} \rightarrow \underbrace{\mathrm{N}}_{\mathrm{R}}$

Scheme 1. $\mathrm{CuFe}_{2} \mathrm{O}_{4} /$ chitosan-catalyzed synthesis of $\alpha$ aminonitrile derivatives $\mathbf{4 a}-\mathbf{l}$.

knowledge, this is the first report on the application of $\mathrm{CuFe}_{2} \mathrm{O}_{4} /$ chitosan as a catalyst in organic reactions. ${ }^{29}$

\section{Experimental}

\subsection{General}

All the solvents, chemicals and reagents were purchased from Merck, Fluka and Aldrich. Melting points were measured on an Electrothermal 9100 apparatus and are uncorrected. IR spectra were recorded on a Shimadzu IR470 spectrometer by the method of $\mathrm{KBr}$ pellets. ${ }^{1} \mathrm{H}$ NMR $(500 \mathrm{MHz})$ and ${ }^{13} \mathrm{C}$ NMR $(125 \mathrm{MHz})$ spectra were recorded in $\mathrm{CDCl}_{3}$ solution with a Bruker DRX-500 Avance spectrometer. The magnetic property was measured on VSM-AGFM (Meghnatis Daghigh Kavir Co., Iran) vibrating sample magnetometer at room temperature. FE-SEM images were obtained with a Seron AIS 2100. EDX spectra were recorded with a Numerix DXP-X10P. The products are known and were identified by comparison of their spectroscopic and analytical data with those of authentic samples.

\subsection{Preparation of $\mathrm{CuFe}_{2} \mathrm{O}_{4} /$ chitosan nanocomposite}

$\mathrm{CuFe}_{2} \mathrm{O}_{4} /$ chitosan nanocomposite was prepared by a twostep process. At first, $\mathrm{CuFe}_{2} \mathrm{O}_{4}$ magnetic nanoparticles were synthesized via reported method described in the literature. ${ }^{30}$ Briefly, $\mathrm{CuFe}_{2} \mathrm{O}_{4}$ nanoparticles were prepared by thermal decomposition of $\mathrm{Cu}\left(\mathrm{NO}_{3}\right)_{2}$ and $\mathrm{Fe}\left(\mathrm{NO}_{3}\right)_{3}$ in water in the presence of sodium hydroxide. $\mathrm{Fe}\left(\mathrm{NO}_{3}\right)_{3} \cdot 9 \mathrm{H}_{2} \mathrm{O}(3.34 \mathrm{~g}$, $8.2 \mathrm{mmol})$ and $\mathrm{Cu}\left(\mathrm{NO}_{3}\right)_{2} .3 \mathrm{H}_{2} \mathrm{O}(1 \mathrm{~g}, 4.1 \mathrm{mmol})$ were dissolved in $75 \mathrm{~mL}$ of distilled water. Then, $3 \mathrm{~g}(75 \mathrm{mmol})$ of $\mathrm{NaOH}$ dissolved in $15 \mathrm{~mL}$ of water was added to metal ion solution at room temperature during $10 \mathrm{~min}$, meanwhile a reddish-black precipitate was formed. Then, the reaction mixture was warmed to $90^{\circ} \mathrm{C}$ and stirred under ultrasonic irradiation for $2 \mathrm{~h}$ and then it was cooled to room temperature. The obtained magnetic nanoparticles were separated by an external magnet. It was washed with distilled water $(3 \times 30 \mathrm{~mL})$ and it was kept in air oven overnight at $80^{\circ} \mathrm{C}$ then it was ground in a mortar-pestle and kept in a furnace at $700^{\circ} \mathrm{C}$ for $5 \mathrm{~h}$ (step up temperature at $2^{\circ} \mathrm{C} / \mathrm{min}$ ) and then cooled to room temperature. At the next step, an aqueous solution of $1.5 \%$ chitosan and $1 \%$ acetic acid was employed. Next, the synthesized ferrite nanopowder (20 wt $\%$ ) was added gradually to a chitosan polymer solution and stirred at room temperature for $6 \mathrm{~h}$. After that, ammonia solution was added dropwise to neutralize the solution. The resulted gel separated from the reaction mixture by a permanent magnet, washed several times with distilled water, and vacuum dried at $50^{\circ} \mathrm{C}$ during $12 \mathrm{~h}$ to obtain the chitosan-supported magnetite nanoparticles.

\subsection{General procedure for the synthesis of 2-(N-anilino)-2-(4-chlorophenyl) acetonitrile $\mathbf{4 a}$}

A mixture of 4-chlorobenzaldehyde $(0.140 \mathrm{~g}, 1 \mathrm{mmol})$, aniline $(0.093 \mathrm{~g}, 1 \mathrm{mmol})$ and TMSCN $(0.120 \mathrm{~g}, 1.2 \mathrm{mmol})$ in $3 \mathrm{~mL}$ of $\mathrm{EtOH}$ was stirred for $15 \mathrm{~min}$ at ambient temperature in the presence of $\mathrm{CuFe}_{2} \mathrm{O}_{4} /$ chitosan nanocomposite $(0.020 \mathrm{~g})$. After completion of the reaction, as indicated by TLC (ethyl acetate-n-hexane, 1:3), the catalyst was removed easily by adsorbing on to the magnetic stirring bar when the stirring was stopped. Then, the solution was filtered off and the filtrate was evaporated under reduced pressure to afford the pure product. Further purification was followed by crystallization from ethanol to give pale yellow crystalline product.

\section{Results and Discussion}

\subsection{Characterization of the nanocatalyst}

3.1a FT-IR Analysis: The FT-IR spectrum of the synthesized nanoparticles is shown in Figure $\mathrm{S} 1$ in Supplementary Information. The spectrum of $\mathrm{CuFe}_{2} \mathrm{O}_{4}$ shows absorption at $580 \mathrm{~cm}^{-1}$ for $\mathrm{Fe}-\mathrm{O}$ band, the intensive broad absorption at $3400 \mathrm{~cm}^{-1}$ represents the stretching mode of $\mathrm{H}_{2} \mathrm{O}$ molecules and $\mathrm{OH}$ groups. The absorption band at $1630 \mathrm{~cm}^{-1}$ refers to the vibration of remainder $\mathrm{H}_{2} \mathrm{O}$ in the sample and less intense absorption band at $1062 \mathrm{~cm}^{-1}$ indicates strong hydrogen bridges. FT-IR spectrum of $\mathrm{CuFe}_{2} \mathrm{O}_{4}$ /chitosan, broad absorption band at 3100-3450 refers to stretching band of $\mathrm{OH}$ and $\mathrm{NH}$ groups of chitosan that bind to copper ferrite nanoparticles. It is also due to $\mathrm{O}-\mathrm{H}$ of nanoparticles. The absorption bands around $1076 \mathrm{~cm}^{-1}$ refer to the stretch vibration of $\mathrm{C}-\mathrm{O}$ bond and the $599 \mathrm{~cm}^{-1}$ band represents the $\mathrm{Fe}-\mathrm{O}$ group of $\mathrm{CuFe}_{2} \mathrm{O}_{4}$.

3.1b EDX analysis: EDX analysis was performed for determination of the elements constitutes catalyst (see Figure S2 in Supplementary Information). As it can be seen in the figure, there is mainly $\mathrm{C}, \mathrm{Fe}, \mathrm{Cu}$ and $\mathrm{O}$ atoms in the nanocomposite.

3.1c FE-SEM analysis: FE-SEM images are used to investigate the surface structure of the nanocomposite. As seen in Figure 1, the distribution of the nanoparticles on the chitosan surface is obvious.

3.1d Thermal stability analysis: Thermogravimetric (TG) curve of $\mathrm{CuFe}_{2} \mathrm{O}_{4}$ /chitosan shows first weight loss at about $100^{\circ} \mathrm{C}$ due to evaporation of adsorbed water in the sample (Figure 2). TG curve shows no weight loss up to about $300^{\circ} \mathrm{C}$. Nanocomposite is thermally stable and suitable for organic reactions. 


\subsection{Application of the nanocatalyst in organic synthetic reaction}

In this work, $\alpha$-aminonitrile derivatives were synthesized by the reaction of different aromatic aldehydes with aniline and trimethylsilyl cyanides in the presence of a catalytic amount of magnetically recoverable chitosan supported $\mathrm{CuFe}_{2} \mathrm{O}_{4}$ nanoparticles $\left(\mathrm{CuFe}_{2} \mathrm{O}_{4} /\right.$ chitosan $)$ in ethanol at ambient temperature. The work-up procedure of the product was easy as the nanocatalyst can be separated simply by an external magnet. To optimize the reaction conditions, a

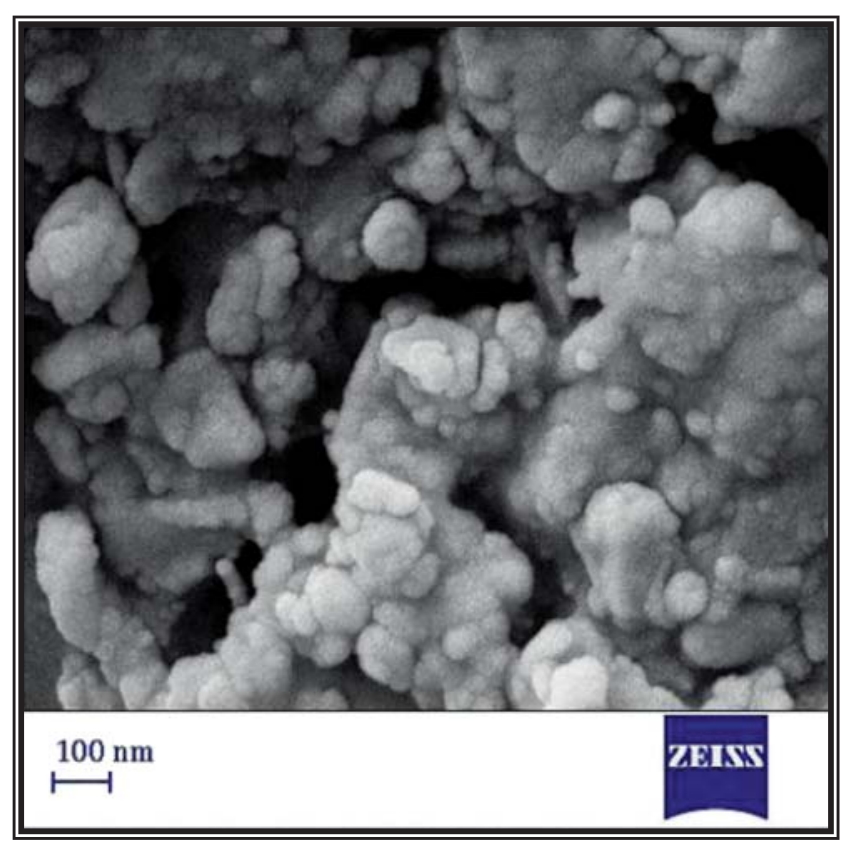

Figure 1. FE-SEM image of $\mathrm{CuFe}_{2} \mathrm{O}_{4} /$ chitosan nanocomposite. series of experiments was performed with variation of different reaction parameters such as solvent and amount of catalyst for a representative condensation of 4-chlorobenzaldehyde $(1 \mathrm{mmol})$, aniline $(1 \mathrm{mmol})$ and TMSCN $(1.2 \mathrm{mmol})$. The results are summarized in Table 1 . The best results were obtained by carrying out the reaction at room temperature in ethanol for $15 \mathrm{~min}$ using $20 \mathrm{mg}$ of $\mathrm{CuFe}_{2} \mathrm{O}_{4} /$ chitosan as the catalyst.

After determining the optimum reaction conditions, the investigation proceeded by performing the reaction between a series of electron rich and deficient aromatic aldehydes, aniline and trimethylsilyl cyanides. To show the common applicability of this method, numerous aldehydes were competently reacted under similar conditions. The results of this study are summarized in Table 2. It was indicated that both electron deficient and electron rich aromatic aldehydes yielded a wide range of $\alpha$-aminonitrile derivatives in good to excellent yields.

Table 1. Optimization of reaction conditions in the reaction of 4-chlorobenzaldehyde, aniline and TMSCN at room temperature.

\begin{tabular}{lcccc}
\hline Entry & Catalyst $(\mathrm{g})$ & Solvent & Time $(\min )$ & Yield $(\%)^{\mathrm{a}}$ \\
\hline 1 & - & EtOH & 60 & Trace \\
2 & 0.004 & EtOH & 15 & 78 \\
3 & 0.008 & EtOH & 15 & 82 \\
4 & 0.01 & EtOH & 15 & 90 \\
5 & 0.02 & EtOH & 15 & 94 \\
6 & 0.03 & EtOH & 15 & 94 \\
7 & 0.02 & $\mathrm{H}_{2} \mathrm{O}$ & 15 & 50 \\
8 & 0.02 & $\mathrm{CH}_{3} \mathrm{CN}$ & 15 & 80 \\
9 & 0.02 & - & 15 & 75 \\
\hline
\end{tabular}

${ }^{a}$ Isolated yield.

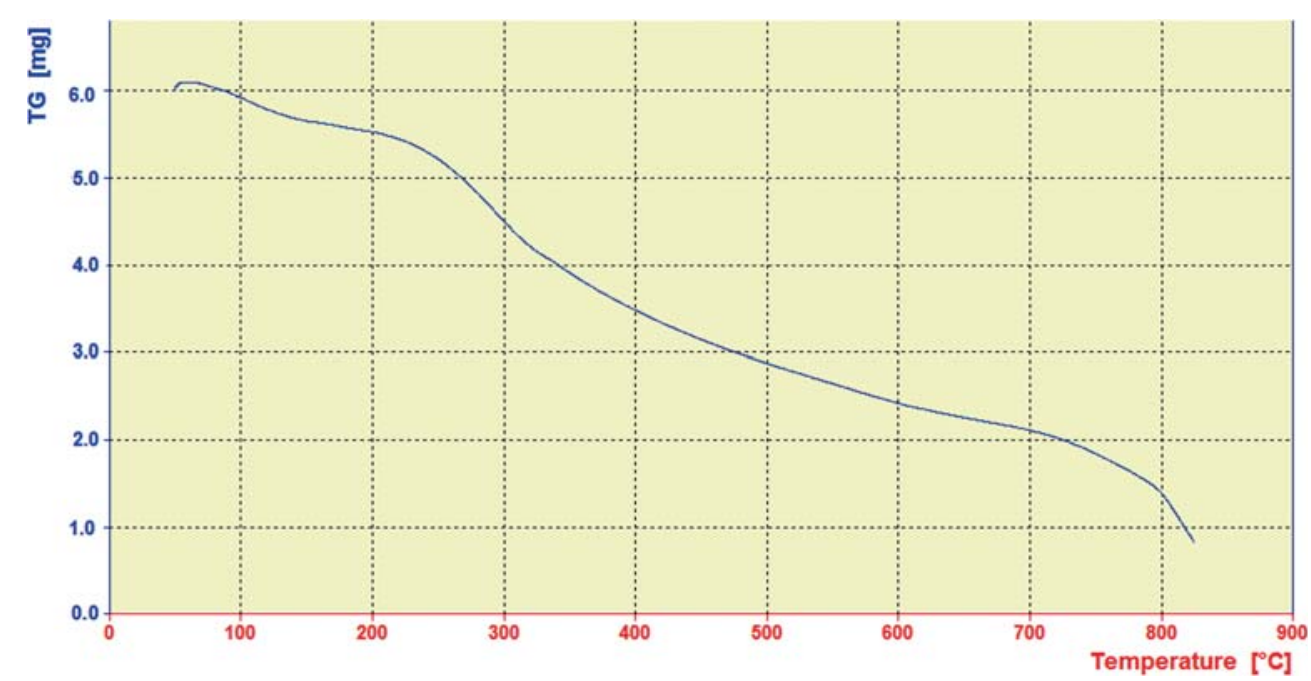

Figure 2. TGA analysis of $\mathrm{CuFe}_{2} \mathrm{O}_{4} /$ chitosan nanocomposite. 
Table 2. Synthesis of $\alpha$-aminonitriles $4 \mathbf{a}-\mathbf{l}$ by using $\mathrm{CuFe}_{2} \mathrm{O}_{4} /$ chitosan at room temperature.

\begin{tabular}{|c|c|c|c|c|c|c|}
\hline \multirow[b]{2}{*}{ Entry } & \multirow[b]{2}{*}{$\mathrm{R}$} & \multirow[b]{2}{*}{ Product } & \multirow[b]{2}{*}{ Time (min) } & \multirow[b]{2}{*}{ Yield $^{\mathrm{a}}(\%)$} & \multicolumn{2}{|c|}{ M.p. $\left({ }^{\circ} \mathrm{C}\right)$} \\
\hline & & & & & Observed & Literature \\
\hline 1 & 4-Chlorophenyl & $4 a$ & 15 & 94 & $111-112$ & $108-110^{31}$ \\
\hline 2 & 4-Bromophenyl & $4 \mathrm{~b}$ & 15 & 94 & $100-101$ & $101-103^{32}$ \\
\hline 3 & Phenyl & $4 c$ & 15 & 85 & 73-75 & $75-76^{31}$ \\
\hline 4 & 4-Methoxylphenyl & $4 d$ & 15 & 91 & $90-91$ & $92-94^{32}$ \\
\hline 5 & 3-Nitrophenyl & $4 \mathrm{e}$ & 15 & 93 & $89-90$ & $90-91^{33}$ \\
\hline 6 & 4-Hydroxyphenyl & $4 \mathrm{f}$ & 15 & 88 & $124-125$ & $120-122^{34}$ \\
\hline 7 & 2-Chlorophenyl & $4 g$ & 15 & 90 & $70-72$ & $63-66^{35}$ \\
\hline 8 & 4-Methylphenyl & $4 \mathrm{~h}$ & 15 & 92 & $70-71$ & $72-74^{35}$ \\
\hline 9 & Cyclohexyl & $4 \mathrm{i}$ & 15 & 86 & $75-76$ & $74-76^{36}$ \\
\hline 10 & 2-Nitrophenyl & $4 j$ & 15 & 91 & $135-137$ & $132-133^{36}$ \\
\hline 11 & 3-Hydroxyphenyl & $4 \mathrm{k}$ & 15 & 87 & Oil & $\mathrm{Oil}^{36}$ \\
\hline 12 & 4-Nitrophenyl & 41 & 15 & 94 & $86-88$ & $90-92^{37}$ \\
\hline
\end{tabular}

${ }^{\mathrm{a}}$ Isolated yield.

\subsection{Catalyst recycling}

The possibility of recycling the catalyst for several times was examined under optimized conditions. It has been shown that $\mathrm{CuFe}_{2} \mathrm{O}_{4} /$ chitosan could be recovered and reused several times in subsequent runs using the same recovered catalyst without a considerable loss of catalytic activity. The isolated yields in five subsequent runs were 94, 91, 89, 87 and $87 \%$, respectively (see Figure S5 in Supplementary Information).

\section{Conclusions}

In summary, for the first time, we have introduced copper ferrite-coated chitosan as a magnetic organicinorganic hybrid nanocatalyst for the multicomponent synthesis of organic compounds. Then, efficient and selective synthesis of $\alpha$-aminonitrile derivatives were carried out by using a variety of aromatic aldehydes, aniline and trimethylsilyl cyanides in the presence of a catalytic amount of the magnetically recoverable chitosan-supported $\mathrm{CuFe}_{2} \mathrm{O}_{4}$ nanoparticles in ethanol at room temperature in high yields.

\section{Supplementary Information (SI)}

Additional experimental data and spectroscopic characterization data are given in the Supplementary Information which is available at www.ias.ac.in/chemsci.

\section{Acknowledgements}

The authors gratefully acknowledge the partial support from the Research Council of the Iran University of Science and Technology.

\section{References}

1. Polshettiwar V and Asefa T 2013 In Nanocatalysis Synthesis and Applications (NJ: John Wiley)

2. (a) Anastas P T and Warner J C 1998 In Principles of green chemistry. Green chemistry: Theory and practice (New York: Oxford University Press) p. 29; (b) Posner G H 1986 Multicomponent one-pot annulations forming 3 to 6 bonds Chem. Rev. 86 831; (b) Dömling A and Ugi I 2000 Multicomponent reactions with isocyanides Angew. Chem. Int. Ed. 39 3168; (c) Shaabani A, Maleki A, Rezayan A H and Sarvary A 2011 Recent progress of isocyanide-based multicomponent reactions in Iran Mol. Divers. 15 41; (d) Altug C, Burnett A K, Caner E, Durust Y, Elliott M C, Glanville R P, Guy C and Westwell A D 2011 An efficient one-pot multicomponent approach to 5-amino-7-aryl-8-nitrothiazolo [3,2-a] pyridines Tetrahedron 679522

3. Kumar M N V R 2000 A review of chitin and chitosan applications React. Funct. Polym. 461

4. (a) Rao D, Sheng Q and Zheng J 2016 Novel nanocomposite of Chitosan-protected platinum nanoparticles immobilized on nickel hydroxide: Facile synthesis and application as glucose electrochemical sensor J. Chem. Sci. 128 1367; (b) Deka B C and Bhattacharyya P K 2016 Reactivity of chitosan derivatives and their interaction with guanine: A computational study J. Chem. Sci. 128589

5. Sahu P K, Sahu P K, Gupta S K and Agarwal D D 2014 Chitosan: An efficient, reusable, and biodegradable catalyst for green synthesis of heterocycles Ind. Eng. Chem. Res. $\mathbf{5 3} 2085$

6. (a) Maleki A, Aghaei M and Ghamari N 2016 Facile synthesis of tetrahydrobenzoxanthenones via a onepot three-component reaction using an eco-friendly and magnetized biopolymer chitosan-based heterogeneous nanocatalyst Appl. Organometal. Chem. 30 939; (b) Maleki A, Aghaei M and Ghamari N 2015 Synthesis of benzimidazolo[2,3- $b$ ]quinazolinone derivatives via a one-pot multicomponent reaction promoted by chitosan-based composite magnetic nanocatalyst Chem. Lett. 44 259; (c) Maleki A, Aghaei M, Ghamari N, 
and Kamalzare M 2016 Efficient synthesis of 2,3dihydroquinazolin-4(1H)-ones in the presence of ferrite/chitosan as a green and reusable nanocatalyst Int. J. Nanosci. Nanotech. 12215

7. (a) Sundeesh N, Sharma S K and Shukla R S 2010 Chitosan as an eco-friendly solid base catalyst for the solvent-free synthesis of jasminaldehyde J. Mol. Catal. A 321 77; (b) Vadekeetil A, Harjai K and Singh V 2015 Synthesis of $\alpha$-acylamino-amidebis(indolyl) methane heterocycles by sequential one pot condensation-Ugi/Passerini reactions and their antimicrobial evaluation Tetrahedron Lett. 56 4445; (c) Kaur N, Shahi S K and Singh V 2015 Synthesis, characterization and photocatalytic activity of magnetically separable $\gamma-\mathrm{Fe}_{2} \mathrm{O}_{3} / \mathrm{N}$, Fe codoped $\mathrm{TiO}_{2}$ heterojunction for degradation of Reactive Blue 4 dye RSC Adv. 561623

8. (a) Shaabani A, Boroujeni M B and Sangachin M H 2015 Cobalt-chitosan: Magnetic and biodegradable heterogeneous catalyst for selective aerobic oxidation of alkyl arenes and alcohols J. Chem. Sci. 127 1927; (b) Thatte C S, Rathnam M V and Pise A C 2014 Chitosanbased Schiff base-metal complexes ( $\mathrm{Mn}, \mathrm{Cu}, \mathrm{Co})$ as heterogeneous, new catalysts for the $\beta$-isophorone oxidation J. Chem. Sci. 126727

9. Maleki A and Paydar R 2016 Bionanostructurecatalyzed one-pot three-component synthesis of 3,4-dihydropyrimidin-2(1H)-one derivatives under solventfree conditions React. Funct. Polym. 109120

10. Shaabani A and Maleki A 2007 Cellulose sulfuric acid as a bio-supported and recyclable solid acid catalyst for the one-pot three-component synthesis of $\alpha$ aminonitriles Appl. Catal. A 331149

11. Gharib A, Noroozi pesyan N, Vojdani fard L and Roshani M 2014 Catalytic synthesis of $\alpha$-aminonitriles using nano copper ferrite $\left(\mathrm{CuFe}_{2} \mathrm{O}_{4}\right)$ under green conditions Org. Chem. Int. 20141

12. Strecker A 1850 Ueber die künstliche Bildung der Milchsäure und einen neuen, dem Glycocoll homologen Körper Ann. Chem. Pharm. 7527

13. Shafran Y M, Bakulev V S and Mokrushin V S 1989 Synthesis and properties of $\alpha$-aminonitriles Russ. Chem. Rev. 58148

14. March J 1995 In Advanced Organic Chemistry $4^{\text {th }}$ ed. (New York: Wiley) p. 965

15. Weinstock L M, Davis P, Handelsman B and Tull R 1967 General synthetic system for 1,2,5-thiadiazoles $J$. Org. Chem. 322823

16. Matier W L, Owens D A, Comer W T, Dietchman D, Ferguson H C, Seidehamel R J and Young J R 1973 Antihypertensive agents. Synthesis and biological properties of 2-amino-4-aryl-2-imidazolines J. Med. Chem. 16901

17. Duthaler R O 1994 Recent developments in the stereoselective synthesis of $\alpha$-aminoacids Tetrahedron $\mathbf{5 0}$ 1539

18. Hatano M, Hattori Y, Furuya Y and Ishihara K 2009 Chiral lanthanum(III)-binaphthyldisulfonate complexes for catalytic enantioselective strecker reaction Org. Lett. 112321

19. Kantam M L, Mahendar K, Sreedhar B and Choudary B M 2008 Catalyst-free synthesis of N-rich heterocycles via multi-component reactions Tetrahedron 643351
20. Simon L and Goodman J M 2009 BINOL-phosphoric acid-catalyzed strecker reaction J. Am. Chem. Soc. 131 4070

21. Zhang G W, Zheng D H, Nie J, Wang T and Ma J 2010 Brønsted acid-catalyzed efficient Strecker reaction of ketones, amines and trimethylsilyl cyanide Org. Biomol. Chem. 81399

22. Jarusiewiez J, Choe Y, Yoo K S, Park C P and Jung K W 2009 Efficient three-component Strecker reaction of aldehydes/ketones via NHC-amidate palladium(II) complex catalysis J. Org. Chem. 742873

23. Karimi B, Maleki A, Elhamifar D, Clark J H and Hunt A J 2010 Self-assembled organic-inorganic hybrid silica with ionic liquid framework: a novel support for the catalytic enantioselective Strecker reaction of imines using $\mathrm{Yb}(\mathrm{OTf})_{3}$-pybox catalyst Chem. Commun. 466947

24. Karmakar B and Banerji J $2010 \mathrm{~K}_{2} \mathrm{PdCl}_{4}$ catalyzed efficient multicomponent synthesis of $\alpha$-aminonitriles in aqueous media Tetrahedron Lett. 512748

25. Cruz-Acosta F, Santos-Exposito A, de Armas P and Garcia-Tellado F 2009 Lewis base-catalyzed threecomponent Strecker reaction on water. An efficient manifold for the direct $\alpha$-cyanoamination of ketones and aldehydes Chem. Commun. 446839

26. Mojtahedi M M, Abaee M S and Alishiri T 2009 Superparamagnetic iron oxide as an efficient catalyst for the one-pot, solvent-free synthesis of $\alpha$-aminonitriles Tetrahedron Lett. $\mathbf{5 0} 2322$

27. Mojtahedi M M, Abaee M S and Abbasi H 2006 Environmentally friendly room temperature strecker reaction: one-pot synthesis of $\alpha$-aminonitriles in ionic liquid J. Iran. Chem. Soc. 393

28. (a) Maleki A $2012 \mathrm{Fe}_{3} \mathrm{O}_{4} / \mathrm{SiO}_{2}$ nanoparticles: An efficient and magnetically recoverable nanocatalyst for the one-pot multicomponent synthesis of diazepines Tetrahedron 68 7827; (b) Maleki A 2013 One-pot multicomponent synthesis of diazepine derivatives using terminal alkynes in the presence of silica-supported superparamagnetic iron oxide nanoparticles Tetrahedron Lett. 54 2055; (c) Maleki A 2014 Synthesis of imidazo [1,2-a] pyridines using $\mathrm{Fe}_{3} \mathrm{O}_{4} / \mathrm{SiO}_{2}$ as an efficient nanomagnetic catalyst via a one-pot multicomponent reaction Helv. Chim. Acta 97 587; (d) Maleki A 2014 One-pot three-component synthesis of pyrido[2', $\left.1^{\prime}: 2,3\right]$ imidazo[4,5-c]isoquinolines using $\mathrm{Fe}_{3} \mathrm{O}_{4} / \mathrm{SiO}_{2}-\mathrm{OSO}_{3} \mathrm{H}$ as an efficient heterogeneous nanocatalyst $R S C A d v .4$ 64169; (e) Maleki A, Ghamari $\mathrm{N}$ and Kamalzare M 2014 Chitosan-supported $\mathrm{Fe}_{3} \mathrm{O}_{4}$ nanoparticles: a magnetically recyclable heterogeneous nanocatalyst for the syntheses of multifunctional benzimidazoles and benzodiazepines $R S C A d v .4$ 9416; (f) Maleki A and Kamalzare M $2014 \mathrm{Fe}_{3} \mathrm{O}_{4}$ /cellulose composite nanocatalyst: Preparation, characterization and application in the synthesis of benzodiazepines Catal. Commun. 53 67; (g) Maleki A, Rahimi R, Maleki S and Hamidi N 2014 Synthesis and characterization of magnetic bromochromate hybrid nanomaterials with triphenylphosphine surface-modified iron oxide nanoparticles and their catalytic application in multicomponent reactions RSC Adv. 4 29765; (h) Maleki A and Paydar R 2015 Graphene oxide-chitosan bionanocomposite: a highly efficient nanocatalyst for the one-pot 
three-component synthesis of trisubstituted imidazoles under solvent-free conditions RSC Adv. 533177

29. Maleki A, Firouzi Haji R and Ghassemi M 2016 Application of chitosan-based magnetic organic-inorganic hybrid nanocatalyst for the multicomponent synthesis of $\alpha$-aminonitriles 20th Electronic Conference on Synthetic Organic Chemistry, 1-30 November; Sciforum Electronic Conference Series, Vol. 20, 2016. doi: 10.3390/ ecsoc-20-a040

30. Dandia A, Jain A K and Sharma S $2013 \mathrm{CuFe}_{2} \mathrm{O}_{4}$ nanoparticles as a highly efficient and magnetically recoverable catalyst for the synthesis of medicinally privileged spiropyrimidine scaffolds $R S C A d v .3$ 2924

31. Majhi A, Kim S S and Kadam S T 2008 Rhodium (III) iodide hydrate catalyzed three-component coupling reaction: synthesis of $\alpha$-aminonitriles from aldehydes, amines, and trimethylsilyl cyanid Tetrahedron 64 5509

32. Rahi T, Baghernejad M and Niknam K 2012 Silicabonded N-propyl diethylenetriamine sulfamic acid as a recyclable solid acid catalyst for the synthesis of $\alpha$ aminonitriles Chin. J. Catal. 331095
33. Karmakar B, Sinhamahaparta A, Baran Panda A, Banerji J and Chowdhury C 2011 Ga-TUD-1: a new heterogeneous mesoporous catalyst for the solventless expeditious synthesis of $\alpha$-aminonitriles Appl. Catal. A 392111

34. Shekouhy M 2012 Sulfuric acid-modified PEG-6000 $\left(\mathrm{PEG}-\mathrm{OSO}_{3} \mathrm{H}\right)$ : an efficient Bronsted acid surfactant combined catalyst for the one-pot three component synthesis of $\alpha$-aminonitriles in water Catal. Sci. Technol. 2 1010

35. Hajipour A R, Ghayeb Y and Sheikhan N $2010 \mathrm{Zr}$ $\left(\mathrm{HSO}_{4}\right) 4$ catalyzed one-pot strecker synthesis of $\alpha$ aminonitriles from aldehydes and ketones under solventfree conditions J. Iran. Chem. Soc. 7447

36. Maleki A, Akhlaghi E and Paydar R 2016 Design, synthesis, characterization and catalytic performance of a new cellulose-based magnetic nanocomposite in the one-pot three-component synthesis of $\alpha$-aminonitriles Appl. Organometal. Chem. 30382

37. Teimouri A, Ghorbanian L and Moatari A 2014 Application of various types of alumina and nano- $\gamma$-alumina sulfuric acid in the synthesis of $\alpha$-aminonitriles derivatives: comparative study Bull. Chem. Soc. Ethiop. 28 441 